OPEN ACCESS

Edited by:

Alexander A. Navarini,

University of Zurich,

Switzerland

Reviewed by:

Jérôme Lamartine,

University of Lyon, France

Michel Simon,

Inserm, France

${ }^{*}$ Correspondence:

Carlo Pincelli

carlo.pincelli@unimore.it

Specialty section:

This article was

submitted to Dermatology,

a section of the journal

Frontiers in Medicine

Received: 21 December 2016 Accepted: 16 February 2017

Published: 07 March 2017

Citation:

Pincelli C (2017) p75 Neurotrophin

Receptor in the Skin: Beyond Its

Neurotrophic Function.

Front. Med. 4:22.

doi: 10.3389/fmed.2017.00022

\section{p75 Neurotrophin Receptor in the Skin: Beyond Its Neurotrophic Function}

\author{
Carlo Pincelli* \\ Laboratory of Cutaneous Biology, Department of Surgical, Medical, Dental and Morphological Sciences, University of \\ Modena and Reggio Emilia, Modena, Italy
}

p75 neurotrophin receptor (p75 NTR), also known as CD271, is the low-affinity receptor that, together with the tyrosine kinase receptor tropomyosin-receptor kinase (Trk), mediate neurotrophin (NT) functions. Beside their classic role in skin innervation, NT and their receptors constitute a complex cutaneous network associated with a number of autocrine and paracrine activities. In this context, the role of p75 ${ }^{\text {NTR }}$ is becoming more and more important. This review will focus on the intriguing functions of p75 NTR in healthy and diseased skin. First, p75 ${ }^{\text {NTR }}$ counterbalances the proliferative and survival activities of its cognate receptor Trk by inducing keratinocyte apoptosis. In addition, p75 NTR identifies an early transit-amplifying (TA) keratinocyte population and plays a critical role in keratinocyte stem cell transition to its progeny as well as in epidermal differentiation. p75 ${ }^{\text {NTR }}$ is absent in psoriatic TA cells, thus rendering these cells resistant to apoptosis. On the other hand, p75 NTR infection restores NT-induced apoptosis in psoriatic keratinocytes. Taken together, these results provide evidence for a critical role of p75NTR in epidermal homeostasis, while its lack may account for the TA defect in psoriasis. While the issue of p75 NTR as a marker of melanoma initiating cells is still to be solved, there is strong evidence that downregulation of this receptor is a precondition to melanoma invasion and metastasis in vitro and in vivo. All in all, this review points to p75 ${ }^{\text {NTR }}$ as a major actor in both physiologic and pathologic conditions at the skin level.

Keywords: p75 neurotrophin receptor, CD271, neurotrophins, skin, epidermis, homeostasis, melanoma, psoriasis

\section{INTRODUCTION}

The neurotrophin (NT) family of growth factors that includes nerve growth factor (NGF), brainderived neurotrophic factor (BDNF), NT-3, and NT-4, plays a fundamental role in the development and maintenance of the nervous system (1). Each NT exerts its activities through two receptor classes: the high-affinity tropomyosin-receptor kinase (Trk) and the common p75 NT receptor (p75 ${ }^{\mathrm{NTR}}$, also known as CD271) (2).

p75 $75^{\text {NTR }}$ belongs to the tumor necrosis factor receptor family and interacts with a variety of ligands and co-receptors to mediate a range of functions, although this interplay is complex and still poorly understood (3). After ligand activation, $\mathrm{p} 75^{\mathrm{NTR}}$ is proteolytically cleaved by $\gamma$-secretase to give intracellular domain (ICD) that is responsible for specific signaling (4). Heterodimerization of $\mathrm{p} 75^{\mathrm{NTR}}$ with Trk increases the NT/Trk interaction affinity, thus augmenting growth and survival functions. In addition, pro-NTs bind to the sortilin-p $75^{\text {NTR }}$ complex and initiate cell death signaling 
(5). ICD in itself can operate independently of the other coreceptors and the functional activity of $\mathrm{p} 75^{\mathrm{NTR}}$ depends on its subcellular localization, on the final location of the fragment (6, 7 ), and on which partners it is associated (8). p $75^{\mathrm{NTR}}$ interacts with a variety of proteins (9) that in turn determine signaling through different pathways (10-12). This interplay allows p $75^{\mathrm{NTR}}$ to play a flexible, but pivotal role in the regulation of multiple activities and ultimately the fate of the cell. The present review will focus on the current knowledge on $\mathrm{p} 75^{\mathrm{NTR}}$ in healthy and diseased skin.

\section{p75 ${ }^{\text {NTR }}$ MEDIATES NT-SUSTAINED SKIN INNERVATION}

In the peripheral nervous system, the survival of sensory and sympathetic neurons largely depends on the production by innervated target of NGF and its cognate NTs (13). Overexpression of NGF in skin determines increase of sensory innervation (14). NGF production is proportional to the innervation density, and it is retrogradely transported to the cell body of the neuron where it regulates its maintenance (15). Also in skin, Trk receptors mediate NTs-enhanced cell survival, while $\mathrm{p} 75^{\mathrm{NTR}}$ promotes cell death of sensory and sympathetic neurons (16). Mice carrying a mutation of gene encoding p $75^{\mathrm{NTR}}$ display a marked decrease in sensory cutaneous innervation, associated with the development of ulcers in the distal extremities (17), indicating a critical role of $\mathrm{p} 75^{\mathrm{NTR}}$ in the survival and functions of sensory neurons. In human skin, the intensity of $\mathrm{p} 75^{\mathrm{NTR}}$ immunoreactivity in sensory nerves is stronger in areas where NGF is upregulated in target cells (18). Moreover, p75 ${ }^{\mathrm{NTR}}$ is strongly increased in sensory fibers in conditions where keratinocytes express high levels of NGF (19).

\section{p75 ${ }^{\text {NTR }}$ OUTSIDE THE NERVOUS SYSTEM}

Beside the classical role of maintaining neuronal cells, NT and their receptors possess a range of functions outside the nervous system. Most non-neuronal cells express NT receptors and respond to NT stimuli, which implies for these neural substances, the role of actual growth factors and/or mediators in a number of physiologic (20) and pathologic conditions $(21,22)$. On the other hand, the function of $\mathrm{p} 75^{\mathrm{NTR}}$ signaling alone or in combination with its co-receptors outside the nervous system has been largely overlooked and remains to be clarified.

\section{NT NETWORK IN THE SKIN}

Over the past 20 years, it has become clear that virtually every cutaneous cell synthesizes and releases NTs and expresses their receptors. Indeed, NGF is produced in basal keratinocytes and is involved in important autocrine functions $(23,24)$. Also, the other NTs are detected in keratinocytes where they exert similar activities (25).

In addition, the important observation that human melanocytes express all NTs and their receptors $(26,27)$ has been confirmed by the critical role these molecules and their receptors play in melanogenesis (28) and melanin production (27). This is further supported by the demonstration that NGF rescue melanocytes from apoptosis (29) and stimulates their migration and dendricity (30). Recently, Byun and co-workers have shown that NGF increases melanogenesis and plays a role in the pathogenesis of melasma (31). Interestingly, NTs and in particular p $75^{\mathrm{NTR}}$ are expressed in neural crest (NC) cells, the melanocyte precursors (32).

While the role of NGF in wound repair has been known for a long time (33), NTs stimulate fibroblasts (34), one of the most important cell involved in this process. Myofibroblasts produce all NT and their receptors. Both p $75^{\mathrm{NTR}}$ and Trks mediate fibroblast proliferation, differentiation, and migration. In addition, NGF or BDNF increase the tensile strength in a collagen gel (35), while tensile stimuli increase NGF in human fibroblasts (36). Recently, p75 $5^{\mathrm{NTR}}$ has been shown to co-immunoprecipitate with the pro-inflammatory phosphodiesterases- 4 in myofibroblasts (37), although the activities of this complex remain to be clarified.

Aloe and Levi-Montalcini originally observed that NGF enhances the number of mast cells in tissues (38). Since then, it is well accepted that there is a close contact between nerves and mast cells to form the "mast cell-nerve unit" that seems to play a key role in physiologic and pathophysiologic processes (39), with particular regard to itch and atopic dermatitis (40). Indeed, high levels of NT-3 are expressed in atopic dermatitis mast cells (41), and $\mathrm{p} 75^{\mathrm{NTR}}$ is induced in lesional atopic mast cells (42).

These findings strongly indicate the presence of a complex NT network in the skin responsible for a number of autocrine and paracrine functions. In this context, a role for $\mathrm{p} 75^{\mathrm{NTR}}$ has recently begun to emerge.

\section{p75 AND HAIR FOLLICLE}

Neurotrophins and their receptors are involved in hair follicle morphogenesis in a complex manner. Consistent with the opposite roles of the two NT receptors, it would appear that NGF/ TrkA promotes an anagen supporting role, whereas proNGF/p75 interaction is associated with a catagen-promoting effect (43). Moreover, NGF, but not BDNF, accelerates hair follicle development (44). On the other hand, BDNF inhibits hair shaft elongation and provokes catagen (45). NGF expression is also observed in keratinocytes of human hair follicles (46), with important implications for morphogenesis (47). Adly and co-workers reported that $\mathrm{p} 75^{\mathrm{NTR}}$ protein displays a hair cycle-dependent fluctuation in human scalp (48), and p $75^{\mathrm{NTR}}$ induces hair follicle involution via apoptosis (49).

\section{p75 ${ }^{\text {NTR }}$ AND EPIDERMAL HOMEOSTASIS}

Epidermal homeostasis is based on a fine balance between keratinocyte proliferation, differentiation, and apoptosis (50). Constant epidermal regeneration is achieved by stem cells that are slow-cycling and possess the capacity of self-renew (51). Keratinocyte stem cells (KSC) reside in the basal layer and generate transit-amplifying (TA) cells that undergo a limited number of cell divisions before committing to terminal differentiation (52), although this model has been recently questioned $(53,54)$. 
Psoriasis is an immune-mediated dermatosis where alterations of epidermal homeostasis account for the main pathologic and clinical outcome. Indeed, psoriasis is characterized by keratinocyte hyperproliferation, abnormal differentiation, and increased resistance to apoptosis (55), resulting in excessive epidermal thickness, the key feature of psoriatic plaque. Thus, psoriasis is a perfect model of altered epidermal homeostasis that can be exploited for evaluating the expression and function of several molecules, including NTs.

Normal human keratinocytes synthesize and secrete all NTs and express their receptors. NGF is predominantly expressed in KSC (25), while TrkA is located only in basal keratinocytes with a uniform pattern (56). On the other hand, $\mathrm{p} 75^{\mathrm{NTR}}$ is expressed in a subpopulation of basal keratinocytes with an irregular distribution (57). NGF levels are increased in psoriatic tissue (58) and keratinocytes (59). TrkA receptor is overexpressed throughout the epidermal layers in psoriatic skin (56), whereas $p 75^{\mathrm{NTR}}$ expression completely disappears in lesional psoriatic epidermis (57). These findings might be consistent with the general concept on the opposing effects Trks and $\mathrm{p} 75^{\mathrm{NTR}}$ mediate in the nervous system (60). The following data confirm that this is actually the case also at the skin level.

Indeed, NGF or NT-3 stimulates keratinocyte growth $(25,61)$, and transfecting HaCat cells with TrkA enhance cell proliferation (62), indicating that NTs act as mitogens through their high-affinity receptor. Consistently, K252, a natural alkaloid that blocks Trk phosphorylation, thus inhibiting NT functions, prevents NGF-induced keratinocyte proliferation (23). In line with the increased expression of Trk and NGF (63) in psoriasis, topical treatment with K252 improves psoriasis in the immunodeficient mouse-human skin model (64). In psoriasis, keratinocyte apoptosis is spontaneously decreased (65), and psoriatic keratinocytes are resistant to apoptosis (66). Recently, PageRank analysis revealed a group of hub genes with anti-apoptotic functions in psoriasis (67).

Endogenous NGF acts as a survival factor for human keratinocytes through Trk receptor, as K252 induces cell death in these cells, by maintaining constant levels of the anti-apoptotic protein Bcl-2 (24). Furthermore, NGF protects keratinocytes from ultraviolet-B-induced apoptosis by preventing the cleavage of the enzyme poly (ADP-ribose) polymerase (61). Taken together, these data support the notion that NTs and Trk receptors mediate proliferative and survival activities in human keratinocytes. Abnormal mitotic and apoptotic processes mediated by NTs lead to the imbalanced epidermal homeostasis resulting in the excessive epidermal thickening observed in psoriasis (Figure 1).

The absence of $\mathrm{p} 75^{\mathrm{NTR}}$ as opposed to the increased Trk expression in lesional psoriatic epidermis (57) supports the hypothesis that an imbalance of the NT receptors could play an important role in the alterations of epidermal homeostasis observed in psoriasis. In normal human skin, binding of $\mathrm{p} 75^{\mathrm{NTR}}$ with proper ligands mediates keratinocyte apoptosis. In fact, $\beta$ amyloid, able to bind directly to $\mathrm{p} 75^{\mathrm{NTR}}$ (68), activates caspase- 3 only in keratinocytes expressing the low-affinity NT receptor. In addition, BDNF or NT-4, which signals only through $\mathrm{p} 75^{\mathrm{NTR}}$, induces apoptosis in human keratinocytes (57). In the nervous system, when both NT receptors are expressed, NT binds to Trk/p75 complex and mediate survival (69). On the other hand, in normal human keratinocytes, where both receptors are expressed, it appears that $\mathrm{p} 75^{\mathrm{NTR}}$ can signal independently of Trk. This is in line with other studies in non-neuronal epithelial tissues. In fact, BDNF was recently shown to induce apoptosis in gingival epithelium via $\mathrm{p} 75^{\mathrm{NTR}}(70)$, and $\mathrm{p} 75^{\mathrm{NTR}}$ mediates apoptosis in prostate cancer cells (71), in the presence of Trk receptors. p75 ${ }^{\mathrm{NTR}}$ independent signal mediating apoptosis in keratinocytes is further confirmed by the co-immunoprecipitation with its interacting protein NRAGE (57) that is known to disrupt $\mathrm{p} 75^{\mathrm{NTR}}$-Trk complex and to cause cell death through JNK-dependent pathway (72). In keeping with this concept, BDNF induces apoptosis in human keratinocytes through the phosphorylation of JNK (57). Taken together, these results indicate that $\mathrm{p} 75^{\mathrm{NTR}}$ counteracts the survival and proliferative activities of Trk receptors, thus contributing to a normal epidermal homeostasis (Figure 1).

In human epidermis, differentiation begins when the transition from KSC to TA cells occurs, although the mechanisms underlying this process are still partially unknown.

p $75^{\text {NTR }}$ is predominantly expressed in the keratinocyte subpopulation enriched in TA cells (57). $\mathrm{p} 75^{\mathrm{NTR}}$-positive keratinocytes sorted from freshly isolated TA cells still retain KSC markers, such as survivin and keratin 15 , while they express less markers of differentiation, as compared to $\mathrm{p} 75^{\mathrm{NTR}}$-negative cells. In addition, $\mathrm{p} 75^{\mathrm{NTR}}$-positive TA cells display a higher proliferative capacity and a better colony forming efficiency, as compared to $\mathrm{p} 75^{\mathrm{NTR}}$-negative cells. Finally, human reconstructed epidermis derived from $\mathrm{p} 75^{\mathrm{NTR}}$-positive TA cells express markers of early differentiation (73). This indicates that $\mathrm{p} 75^{\mathrm{NTR}}$ identifies a population of early TA cells. A population of early TA has been already detected in the hair follicle (74) and in the interfollicular epidermis (75) and appears to be critical in the first steps of the differentiation process $(76)$. p $75^{\mathrm{NTR}}$ protein that exerts its activities at the boundary between KSC and TA could function as early trigger of keratinocyte differentiation. In fact, silencing p $75^{\mathrm{NTR}}$ prevents calcium-induced keratinocyte differentiation and converts TA cells into a KSC phenotype. Moreover, overexpression of $\mathrm{p} 75^{\mathrm{NTR}}$ in KSC results in a keratinocyte subpopulation with the features of TA cells (73). These results indicate that $\mathrm{p} 75^{\mathrm{NTR}}$ could act as a "switch on-off" protein that critically regulates KSC-progeny transition and differentiation in human epidermis (Figure 1).

Excessive expansion of the TA cells compartment has been recently described in psoriatic skin (77), where a defect in TA subpopulation seems to account for the epidermal abnormalities observed in the disease (78). In addition, in silico studies have simulated psoriasis by altering the TA cells (79), and psoriatic TA cells are more advanced in their life cycle than their normal counterpart (80). p $75^{\mathrm{NTR}}$ levels are strikingly reduced in psoriatic TA (57), and the lack of $\mathrm{p} 75^{\mathrm{NTR}}$ seems to account for the reduced apoptosis of psoriatic keratinocytes. Indeed, BDNF fail to induce cell death in these cells, while overexpression of $\mathrm{p} 75^{\mathrm{NTR}}$ restores their susceptibility to apoptosis (73). These findings suggest that alterations of the TA cell in psoriasis are at least in part due to a defect in $\mathrm{p} 75^{\mathrm{NTR}}$. Interestingly, skin equivalent models derived from $\mathrm{p} 75^{\mathrm{NTR}}$-negative TA cells display a psoriasiform 


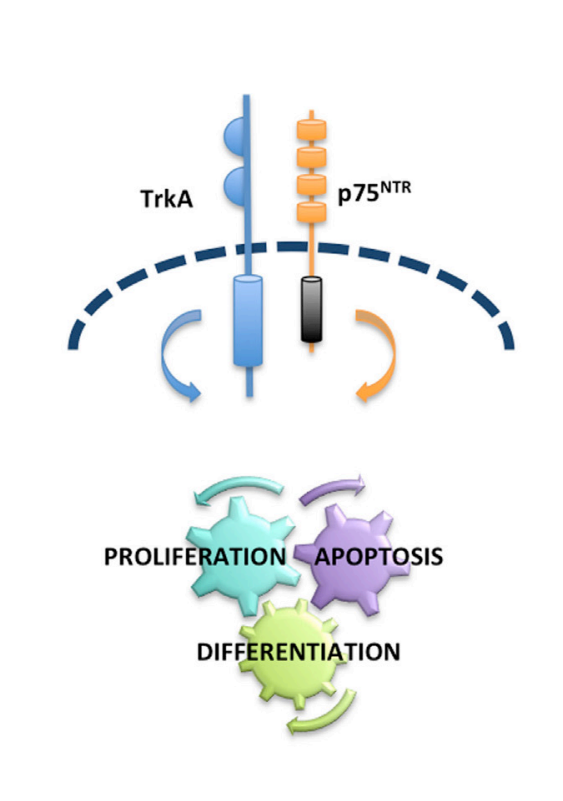

NORMAL EPIDERMAL HOMEOSTASIS

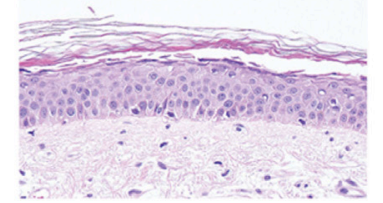

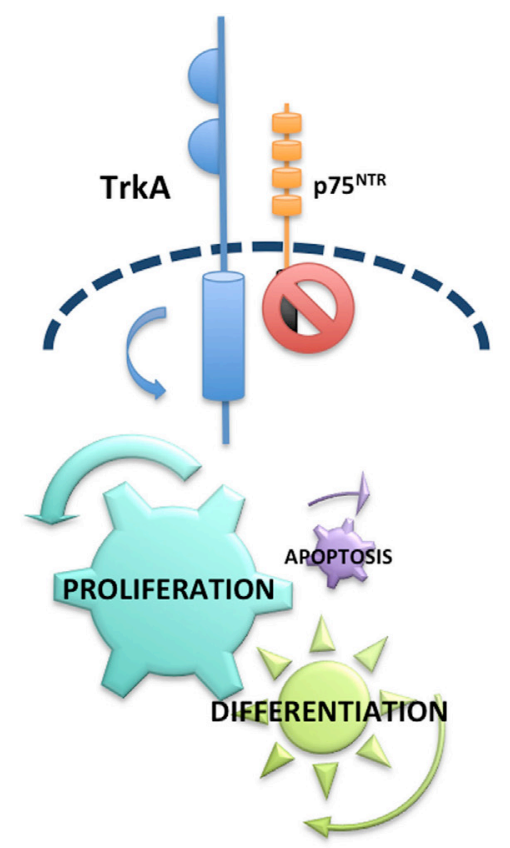

ALTERED EPIDERMAL HOMEOSTASIS

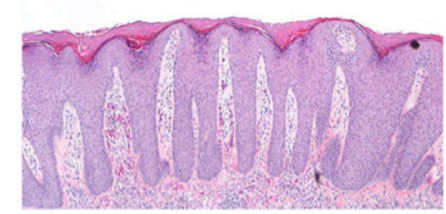

FIGURE 1 | p75 ${ }^{\text {NTR }}$ in epidermal homeostasis and psoriasis. In normal epidermis, there is a balance between p75 ${ }^{\text {NTR }}$ and tropomyosin-receptor kinase (Trk) receptors that controls proliferation, differentiation, and apoptosis and allows a perfect homeostasis. Upregulation of Trk and lack of p75 ${ }^{N T R}$ cause hyperproliferation, abnormal differentiation and reduced apoptosis that in turn are responsible for the altered epidermal homeostasis typical of psoriasis.

phenotype (73) in line with the absence of the receptor protein in psoriasis (57). Because p $75^{\mathrm{NTR}}$ plays a critical role in the early keratinocyte differentiation, it is tempting to speculate that the intrinsic defects in psoriatic epidermis occur in the early TA cells where the absence of $\mathrm{p} 75^{\mathrm{NTR}}$ may account for the altered epidermal homeostasis of the disease. It has been shown that when keratinocytes exit the niche, they could undergo either differentiation or programmed cell death (81). Although p $75^{\mathrm{NTR}}$ is clearly involved in both processes in human epidermis, the different triggers and pathways associated with the functions of the receptor remain to be elucidated.

\section{p75 ${ }^{\text {NTR }}$ AND MELANOMA: MORE THAN JUST A MARKER}

Melanoma cell lines synthesize and secrete all NTs and express NT receptors (82). p $75^{\mathrm{NTR}}$ was first isolated from a melanoma cell line, and it has become a useful tool for immunohistochemical diagnosis of melanoma (83). High degree of $\mathrm{p} 75^{\mathrm{NTR}}$ expression allows a better diagnosis of desmoplastic melanoma (84) and the distinction between spindle melanoma and other spindle cell tumors (85).
According to the "cancer stem cell" theory, a distinct subpopulation of melanoma cells (melanoma initiating cells, MIC) would account for the high tumorigenic properties, tumor heterogeneity, invasiveness, and drug resistance (86). p $75^{\mathrm{NTR}}$ has received a special attention as a possible MIC marker because it is a marker of NC cells, the melanocyte precursors (87), and for the similarities between NC stem cells and melanoma cells (88). Yet, whether p $75^{\text {NTR }}$ identifies a group of highly tumorigenic MIC has not been clarified. It was first demonstrated that MIC express high levels of $\mathrm{p} 75^{\mathrm{NTR}}$ and $\mathrm{p} 75^{\mathrm{NTR}}$-positive, but not $\mathrm{p} 75^{\mathrm{NTR}}$-negative transplanted melanoma cells are capable of inducing metastasis in vivo (89). On the other hand, Quintana and co-workers could not confirm these data, by showing that $\mathrm{p} 75^{\mathrm{NTR}}$-positive or $\mathrm{p} 75^{\mathrm{NTR}}$-negative melanoma cells have the same tumorigenic potential (90). Recently, Boyle and colleagues, using different patient-derived xenograft assays, have clearly shown that $\mathrm{p} 75^{\mathrm{NTR}}$-negative and p75 $5^{\text {NTR }}$-positive melanoma cells from each of the patients had similar tumorigenic activity, concluding that $\mathrm{p} 75^{\mathrm{NTR}}$ expression is unstable and not associated with increased tumorigenicity (91). This work also questions its role as a marker of melanoma aggressiveness (91). Consistently, p75 ${ }^{\mathrm{NTR}}$ expression inversely correlates with hypoxia and melanoma invasiveness in vivo (92). 


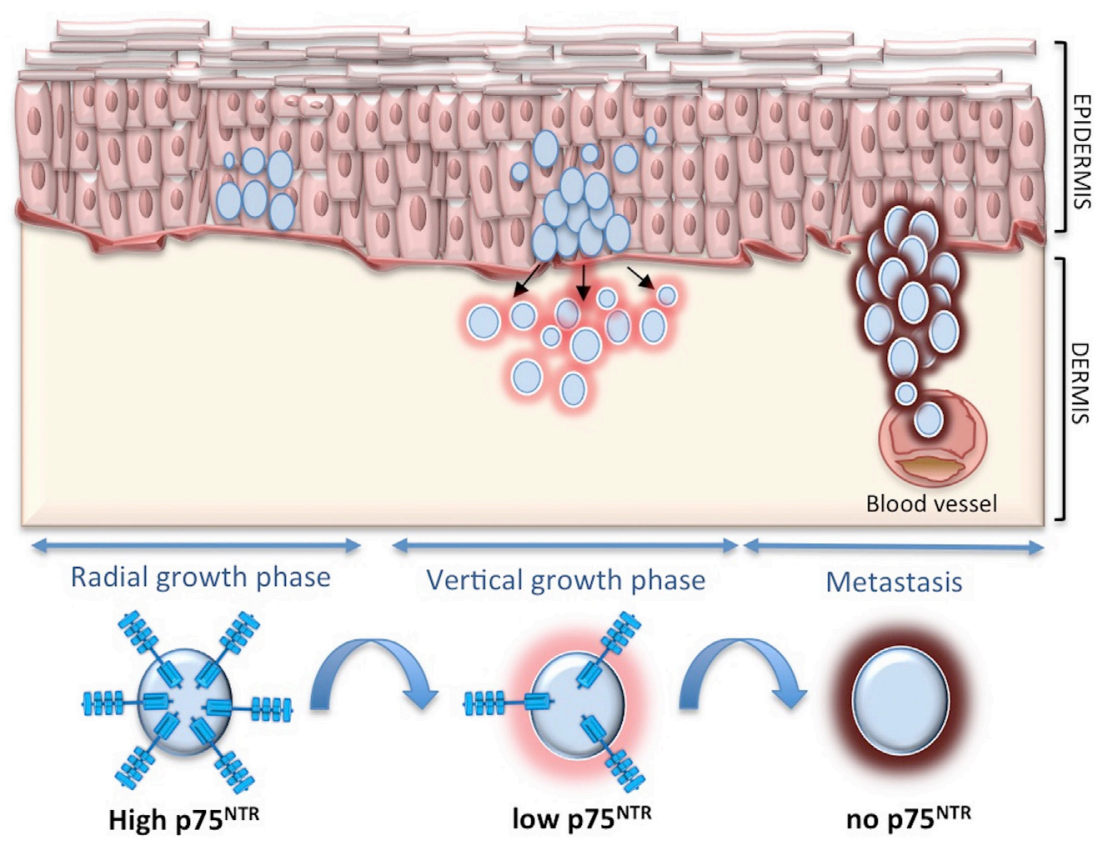

FIGURE 2 | p75 neurotrophin receptor (p75 ${ }^{\text {NTR }}$ ) and melanoma. p75 ${ }^{\mathrm{NTR}}$ is associated with less aggressive melanoma, while it tends to decrease and disappear during melanoma invasion and metastasis.

To definitely assess the role of $\mathrm{p} 75^{\mathrm{NTR}}$ in melanoma, we have recently carried out an extensive study in vitro and in vivo (93). In skin equivalent models, $\mathrm{p} 75^{\mathrm{NTR}}$ is highly expressed in early melanomas at the epidermal level and tends to disappear when melanoma starts to invade the dermis. In addition, $\mathrm{p} 75^{\mathrm{NTR}}$ is completely absent in skin reconstructs derived from metastatic cell lines. $\mathrm{p} 75^{\mathrm{NTR}}$ expression is highest in spheroids derived from primary melanoma cells, it decreases in cells derived from metastatic melanomas to disappear in highly invasive spheroids. p $75^{\text {NTR }}$-negative cells show greater proliferation and invasiveness in vitro and are associated with a higher number of metastases in zebrafish, as compared with $\mathrm{p} 75^{\mathrm{NTR}}$-positive cells. Moreover, silencing $\mathrm{p} 75^{\mathrm{NTR}}$ induces a more aggressive phenotype in spheroids and in the animal model. By contrast, $\mathrm{p} 75^{\mathrm{NTR}}$ overexpression reduces invasiveness in vitro and strikingly reduces the number of metastases in zebrafish. This seems to indicate that $\mathrm{p} 75^{\mathrm{NTR}}$ switch off is critical for melanoma progression and metastasis (Figure 2).

\section{CONCLUSION}

There is compelling evidence that, in the context of the skin NT network, $\mathrm{p} 75^{\mathrm{NTR}}$ is a major actor in both physiological and pathological conditions. In healthy skin, $\mathrm{p} 75^{\text {NTR }}$-triggered differentiation and de-differentiation during KSC to progeny transition

\section{REFERENCES}

1. Bothwell M. NGF, BDNF, NT3, and NT4. Handb Exp Pharmacol (2014) 220:3-15. doi:10.1007/978-3-642-45106-5_1 awaits confirmation in other epidermal stem cell compartments as well as in the mouse model. In addition, more studies are needed to understand the mechanisms underlying the absence of $\mathrm{p} 75^{\mathrm{NTR}}$ protein in psoriasis, and whether the lack of the receptor, that is critical for epidermal homeostasis, is associated with a psoriatic phenotype also in vivo.

While the downregulation of $\mathrm{p} 75^{\mathrm{NTR}}$ as a precondition for melanoma progression and metastasis is unquestionable, the molecular mechanisms associated with this function are not fully clarified. The low levels of $\beta_{1}$ integrin and the decreased of cell-to-cell adhesion in the absence of $\mathrm{p} 75^{\mathrm{NTR}}$ could predispose melanoma to increased invasiveness (93). Furthermore, melanoma is characterized by an alteration of the apoptotic machinery. The lack of $\mathrm{p} 75^{\mathrm{NTR}}$ that exerts pro-apoptotic functions in melanoma (94), could favor tumor cell survival and metastasis.

\section{AUTHOR CONTRIBUTIONS}

The author confirms being the sole contributor of this work and approved it for publication.

\section{ACKNOWLEDGMENTS}

The author would like to thank Roberta Lotti and Annalisa Saltari for critical revising and editing of the manuscript.

2. Marchetti L, Luin S, Bonsignore F, de Nadai T, Beltram F, Cattaneo A. Ligandinduced dynamics of neurotrophin receptors investigated by single-molecule imaging approaches. Int JMol Sci (2015) 16(1):1949-79. doi:10.3390/ ijms16011949 
3. Ibáñez CF, Simi A. p75 neurotrophin receptor signaling in nervous system injury and degeneration: paradox and opportunity. Trends Neurosci (2012) 35(7):431-40. doi:10.1016/j.tins.2012.03.007

4. Vilar M, Mira H. Regulation of neurogenesis by neurotrophins during adulthood: expected and unexpected roles. Front Neurosci (2016) 10:26. doi:10.3389/fnins.2016.00026

5. Meeker R, Williams K. Dynamic nature of the p75 neurotrophin receptor in response to injury and disease. J Neuroimmune Pharmacol (2014) 9(5):615-28. doi:10.1007/s11481-014-9566-9

6. Bronfman FC, Fainzilber M. Multi-tasking by the p75 neurotrophin receptor: sortilin things out? EMBO Rep (2004) 5(9):867-71. doi:10.1038/ sj.embor.7400219

7. Skeldal S, Matusica D, Nykjaer A, Coulson EJ. Proteolytic processing of the p75 neurotrophin receptor: a prerequisite for signalling? Neuronal life, growth and death signalling are crucially regulated by intra-membrane proteolysis and trafficking of p75(NTR). Bioessays (2011) 33(8):614-25. doi:10.1002/ bies. 201100036

8. Vilar M, Charalampopoulos I, Kenchappa RS, Reversi A, Klos-Applequist JM, Karaca E, et al. Ligand-independent signaling by disulfide-crosslinked dimers of the p75 neurotrophin receptor. J Cell Sci (2009) 122:3351-7. doi:10.1242/ jcs.055061

9. Barker PA. p75NTR is positively promiscuous: novel partners and new insights. Neuron (2004) 42:529-33. doi:10.1016/j.neuron.2004.04.001

10. Troy CM, Friedman JE, Friedman WJ. Mechanisms of p75-mediated death of hippocampal neurons. Role of caspases. J Biol Chem (2002) 277:34295-302. doi:10.1074/jbc.M205167200

11. Becker EB, Howell J, Kodama Y, Barker PA, Bonni A. Characterization of the c-Jun N-terminal kinase-BimEL signaling pathway in neuronal apoptosis. J Neurosci (2004) 24(40):8762-70. doi:10.1523/JNEUROSCI.295304.2004

12. Linggi MS, Burke TL, Williams BB, Harrington A, Kraemer R, Hempstead BL, et al. Neurotrophin receptor interacting factor (NRIF) is an essential mediator of apoptotic signaling by the p76 neurotrophic receptor. J Biol Chem (2005) 280(14):13801-8. doi:10.1074/jbc.M410435200

13. Delcroix JD, Valletta JS, Wu C, Hunt SJ, Kowal AS, Mobley WC. NGF signaling in sensory neurons: evidence that early endosomes carry NGF retrograde signals. Neuron (2003) 39:69-84. doi:10.1016/S0896-6273(03)00397-0

14. Davis BM, Fundin BT, Albers KM, Goodness TP, Cronk KM, Rice FL. Overexpression of nerve growth factor in skin causes preferential increases among innervation to specific sensory targets. J Comp Neurol (1997) 387(4):489-506. doi:10.1002/(SICI)1096-9861(19971103)387:4<489::AIDCNE2>3.0.CO;2-Z

15. Wyatt SL, Spori B, Vizard TN, Davies AM. Selective regulation of nerve growth factor expression in developing cutaneous tissue by early sensory innervation. Neural Dev (2011) 6:1-8. doi:10.1186/1749-8104-6-18

16. Bothwell M. Neurotrophin function in skin. J Investig Dermatol Symp Proc (1997) 2(1):27-30. doi:10.1038/jidsymp.1997.7

17. Lee KF, Li E, Huber LJ, Landis SC, Sharpe AH, Chao MV, et al. Targeted mutation of the gene encoding the low affinity NGF receptor p75 leads to deficits in the peripheral sensory nervous system. Cell (1992) 69(5):737-49. doi:10.1016/0092-8674(92)90286-L

18. Dou YC, Hagströmer L, Emtestam L, Johansson O. Increased nerve growth factor and its receptors in atopic dermatitis: an immunohistochemical study. Arch Dermatol Res (2006) 298(1):31-7. doi:10.1007/s00403-006-0657-1

19. Raychaudhuri SP, Raychaudhuri SK. Role of NGF and neurogenic inflammation in the pathogenesis of psoriasis. Prog Brain Res (2004) 146:433-7. doi:10.1016/S0079-6123(03)46027-5

20. Aloe L, Rocco ML, Bianchi P, Manni L. Nerve growth factor: from the early discoveries to the potential clinical use. J Transl Med (2012) 10(239):1-15. doi:10.1186/1479-5876-10-239

21. Scuri M, Samsell L, Piedimonte G. The role of neurotrophins in inflammation and allergy. Inflamm Allergy Drug Targets (2010) 9(3):173-80. doi:10.2174/187152810792231913

22. Seidel MF, Lane NE. Control of arthritis pain with anti-nerve-growth factor: risk and benefit. Curr Rheumatol Rep (2012) 14(6):583-8. doi:10.1007/ s11926-012-0289-8

23. Pincelli C, Sevignani C, Manfredini R, Grande A, Fantini F, Bracci-Laudiero L, et al. Expression and function of nerve growth factor and nerve growth factor receptor on cultured keratinocytes. J Invest Dermatol (1994) 103(1): 13-8. doi:10.1111/1523-1747.ep12388914

24. Pincelli C, Haake AR, Benassi L, Grassilli E, Magnoni C, Ottani D, et al. Autocrine nerve growth factor protects human keratinocytes from apoptosis through its high affinity receptor (TRK): a role for BCL-2. J Invest Dermatol (1997) 109(6):757-64. doi:10.1111/1523-1747.ep12340768

25. Marconi A, Terracina M, Fila C, Franchi J, Bonté F, Romagnoli G, et al. Expression and function of neurotrophins and their receptors in cultured human keratinocytes. J Invest Dermatol (2003) 121(6):1515-21. doi:10.1111/j.1523-1747.2003.12624.x

26. Yaar M, Eller MS, DiBenedetto P, Reenstra WR, Zhai S, McQuaid T, et al. The trk family of receptors mediates nerve growth factor and neurotrophin-3 effects in melanocytes. J Clin Invest (1994) 94(4):1550-62. doi:10.1172/ JCI117496

27. Marconi A, Panza MC, Bonnet-Duquennoy M, Lazou K, Kurfurst R, Truzzi F, et al. Expression and function of neurotrophins and their receptors in human melanocytes. Int J Cosmet Sci (2006) 28(4):255-61. doi:10.1111/j.1467-2494.2006.00321.x

28. Yamaguchi Y, Hearing VJ. Physiological factors that regulate skin pigmentation. Biofactors (2009) 35(2):193-9. doi:10.1002/biof.29

29. Zhai S, Yaar M, Doyle SM, Gilchrest BA. Nerve growth factor rescues pigment cells from ultraviolet-induced apoptosis by upregulating BCL-2 levels. Exp Cell Res (1996) 224(2):335-43. doi:10.1006/excr.1996.0143

30. Yaar M, Grossman K, Eller M, Gilchrest BA. Evidence for nerve growth factor-mediated paracrine effects in human epidermis. J Cell Biol (1991) 115:821-8. doi:10.1083/jcb.115.3.821

31. Byun JW, Park IS, Choi GS, Shin J. Role of fibroblast-derived factors in the pathogenesis of melasma. Clin Exp Dermatol (2016) 41(6):601-9. doi:10.1111/ ced. 12874

32. Pelaez D, Huang CY, Cheung HS. Isolation of pluripotent neural crest-derived stem cells from adult human tissues by connexin-43 enrichment. Stem Cells Dev (2013) 22(21):2906-14. doi:10.1089/scd.2013.0090

33. Matsuda H, Koyama H, Sato H, Sawada J, Itakura A, Tanaka A, et al. Role of nerve growth factor in cutaneous wound healing: accelerating effects in normal and healing-impaired diabetic mice. J Exp Med (1998) 187(3):297-306. doi:10.1084/jem.187.3.297

34. Micera A, Vigneti E, Pickholtz D, Reich R, Pappo O, Bonini S, et al. Nerve growth factor displays stimulatory effects on human skin and lung fibroblasts, demonstrating a direct role for this factor in tissue repair. Proc Natl Acad Sci US A (2001) 98(11):6162-7. doi:10.1073/pnas.101130898

35. Palazzo E, Marconi A, Truzzi F, Dallaglio K, Petrachi T, Humbert P, et al. Role of neurotrophins on dermal fibroblast survival and differentiation. J Cell Physiol (2012) 227(3):1017-25. doi:10.1002/jcp.22811

36. Kim M, Shin DW, Shin H, Noh M, Shin JH. Tensile stimuli increase nerve growth factor in human dermal fibroblasts independent of tension-induced TGF $\beta$ production. Exp Dermatol (2013) 22(1):72-4. doi:10.1111/ exd.12064

37. Schafer PH, Truzzi F, Parton A, Wu L, Kosek J, Zhang LH, et al. Phosphodiesterase 4 in inflammatory diseases: effects of apremilast in psoriatic blood and in dermal myofibroblasts through the PDE4/CD271 complex. Cell Signal (2016) 28(7):753-63. doi:10.1016/j.cellsig.2016.01.007

38. Aloe L, Levi-Montalcini R. Mast cells increase in tissues of neonatal rats injected with the nerve growth factor. Brain Res (1977) 133(2):358-66. doi:10.1016/0006-8993(77)90772-7

39. Forsythe P, Bienenstock J. The mast cell-nerve functional unit: a key component of physiologic and pathophysiologic responses. Chem Immunol Allergy (2012) 98:196-221. doi:10.1159/000336523

40. Yamaguchi J, Aihara M, Kobayashi Y, Kambara T, Ikezawa Z. Quantitative analysis of nerve growth factor (NGF) in the atopic dermatitis and psoriasis horny layer and effect of treatment on NGF in atopic dermatitis. J Dermatol Sci (2009) 53(1):48-54. doi:10.1016/j.jdermsci.2008.08.011

41. Quarcoo D, Fischer TC, Peckenschneider N, Groneberg DA, Welker P. High abundances of neurotrophin 3 in atopic dermatitis mast cell. J Occup Med Toxicol (2009) 4(8):1-7. doi:10.1186/1745-6673-4-8

42. Fischer TC, Lauenstein HD, Serowka F, Pilzner C, Groneberg DA, Welker P. Pan-neurotrophin receptor p75NTR expression is strongly induced in lesional atopic mast cells. Clin Exp Allergy (2008) 38(7):1168-73. doi:10.1111/j.1365-2222.2008.02994.x 
43. Peters EM, Hendrix S, Gölz G, Klapp BF, Arck PC, Paus R. Nerve growth factor and its precursor differentially regulate hair cycle progression in mice. J Histochem Cytochem (2006) 54(3):275-88. doi:10.1369/jhc.4A6585.2005

44. Botchkareva NV, Botchkarev VA, Albers KM, Metz M, Paus R. Distinct roles for nerve growth factor and brain-derived neurotrophic factor in controlling the rate of hair follicle morphogenesis. J Invest Dermatol (2000) 114(2):314-20. doi:10.1046/j.1523-1747.2000.00864.x

45. Peters EM, Hansen MG, Overall RW, Nakamura M, Pertile P, Klapp BF, et al. Control of human hair growth by neurotrophins: brain-derived neurotrophic factor inhibits hair shaft elongation, induces catagen, and stimulates follicular transforming growth factor beta2 expression. J Invest Dermatol (2005) 124(4):675-85. doi:10.1111/j.0022-202X.2005.23648.x

46. Adly MA, Assaf HA, Nada EA, Soliman M, Hussein M. Expression of nerve growth factor and its high-affinity receptor, tyrosine kinase A proteins, in the human scalp skin. J Cutan Pathol (2006) 33(8):559-68. doi:10.1111/j.1600-0560.2006.00443.x

47. Botchkarev VA, Botchkareva NV, Peters EM, Paus R. Epithelial growth control by neurotrophins: leads and lessons from the hair follicle. Prog Brain Res (2004) 146:493-513. doi:10.1016/S0079-6123(03)46031-7

48. Adly MA, Assaf HA, Hussein MR. Expression pattern of p75 neurotrophin receptor protein in human scalp skin and hair follicles: hair cycle-dependent expression. J Am Acad Dermatol (2009) 60(1):99-109. doi:10.1016/j. jaad.2008.09.060

49. Peters EM, Stieglitz MG, Liezman C, Overall RW, Nakamura M, Hagen E, et al. p75 neurotrophin receptor-mediated signaling promotes human hair follicle regression (catagen). Am J Pathol (2006) 168(1):221-34. doi:10.2353/ ajpath.2006.050163

50. Livshits G, Kobielak A, Fuchs E. Governing epidermal homeostasis by coupling cell-cell adhesion to integrin and growth factor signaling, proliferation, and apoptosis. Proc Natl Acad Sci U S A (2012) 109:4886-91. doi:10.1073/ pnas. 1202120109

51. Pincelli C, Marconi A. Keratinocyte stem cells: friends and foes. J Cell Physiol (2010) 225(2):310-5. doi:10.1002/jcp.22275

52. Kaur P. Interfollicular epidermal stem cells: identification, challenges, potential. J Invest Dermatol (2006) 126(7):1450-8. doi:10.1038/sj.jid.5700184

53. Clayton E, Doupé DP, Klein AM, Winton DJ, Simons BD, Jones PH. A single type of progenitor cell maintains normal epidermis. Nature (2007) 446:185-9. doi:10.1038/nature05574

54. Sada A, Jacob F, Leung E, Wang S, White BS, Shalloway D, et al. Defining the cellular lineage hierarchy in the interfollicular epidermis of adult skin. Nat Cell Biol (2016) 18(6):619-31. doi:10.1038/ncb3359

55. Simonart T, Heenen M, Lejeune O. Epidermal kinetic alterations required to generate the psoriatic phenotype: a reappraisal. Cell Prolif(2010) 43(3):321-5. doi:10.1111/j.1365-2184.2010.00672.x

56. Pincelli C. Nerve growth factor and keratinocytes: a role in psoriasis. Eur J Dermatol (2000) 10(2):85-90.

57. Truzzi F, Marconi A, Atzei P, Panza MC, Lotti R, Dallaglio K, et al. p75 neurotrophin receptor mediates apoptosis in transit-amplifying cells and its overexpression restores cell death in psoriatic keratinocytes. Cell Death Differ (2011) 18(6):948-58. doi:10.1038/cdd.2010.162

58. Fantini F, Magnoni C, Bracci-Laudiero L, Pincelli C. Nerve growth factor is increased in psoriatic skin. J Invest Dermatol (1995) 105(6):854-5. doi:10.1111/1523-1747.ep12326689

59. Raychaudhuri SP, Jiang WY, Farber EM. Psoriatic keratinocytes express high levels of nerve growth factor. Acta Derm Venereol (1998) 78(2):84-6. doi:10.1080/000155598433368

60. Ceni C, Unsain N, Zeinieh MP, Barker PA. Neurotrophins in the regulation of cellular survival and death. Handb Exp Pharmacol (2014) 220:193-221. doi:10.1007/978-3-642-45106-5_8

61. Marconi A, Vaschieri C, Zanoli S, Giannetti A, Pincelli C. Nerve growth factor protects human keratinocytes from ultraviolet-B-induced apoptosis. J Invest Dermatol (1999) 113(6):920-7. doi:10.1046/j.1523-1747.1999.00773.x

62. Pincelli C, Marconi A. Autocrine nerve growth factor in human keratinocytes. J Dermatol Sci (2000) 22(2):71-9. doi:10.1016/S0923-1811(99)00065-1

63. Raychaudhuri SP, Jiang WY, Raychaudhuri SK. Revisiting the Koebner phenomenon: role of NGF and its receptor system in the pathogenesis of psoriasis. Am J Pathol (2008) 172(4):961-71. doi:10.2353/ajpath.2008.070710

64. Raychaudhuri SP, Sanyal M, Weltman H, Kundu-Raychaudhuri S. K252a, a high-affinity nerve growth factor receptor blocker, improves psoriasis: an in vivo study using the severe combined immunodeficient mouse-human skin model. J Invest Dermatol (2004) 122(3):812-9. doi:10.1111/j.0022-202X.2003. 12602.x

65. Laporte M, Galand P, Fokan D, de Graef C, Heenen M. Apoptosis in established and healing psoriasis. Dermatology (2000) 200(4):314-6. doi:10.1159/000018394

66. Wrone-Smith T, Mitra RS, Thompson CB, Jasty R, Castle VP, Nickoloff BJ. Keratinocytes derived from psoriatic plaques are resistant to apoptosis compared with normal skin. Am J Pathol (1997) 151(5):1321-9.

67. Zeng X, Zhao J, Wu X, Shi H, Liu W, Cui B, et al. PageRank analysis reveals topologically expressed genes correspond to psoriasis and their functions are associated with apoptosis resistance. Mol Med Rep (2016) 13(5):3969-76. doi:10.3892/mmr.2016.4999

68. Yaar M, Zhai S, Pilch PF, Doyle SM, Eisenhauer PB, Fine RE, et al. Binding of beta-amyloid to the $\mathrm{p} 75$ neurotrophin receptor induces apoptosis. A possible mechanism for Alzheimer's disease. J Clin Invest (1997) 100:2333-40. doi:10.1172/JCI119772

69. Chao MV, Bothwell M. Neurotrophins: to cleave or not to cleave. Neuron (2002) 33:9-12. doi:10.1016/S0896-6273(01)00573-6

70. Kashiwai K, Kajiya M, Matsuda S, Ouhara K, Takeda K, Takata T, et al. Distinction between cell proliferation and apoptosis signals regulated by brain-derived neurotrophic factor in human periodontal ligament cells and gingival epithelial cells. J Cell Biochem (2016) 117(7):1543-55. doi:10.1002/ jcb. 25446

71. Khwaja FS, Quann EJ, Pattabiraman N, Wynne S, Djakiew D. Carprofen induction of p75NTR-dependent apoptosis via the $\mathrm{p} 38$ mitogen-activated protein kinase pathway in prostate cancer cells. Mol Cancer Ther (2008) 7(11):3539-45. doi:10.1158/1535-7163.MCT-08-0512

72. Salehi AH, Xanthoudakis S, Barker PA. NRAGE, a p75 neurotrophin receptor-interacting protein, induces caspase activation and cell death through a JNK-dependent mitochondrial pathway. J Biol Chem (2002) 277:48043-50. doi:10.1074/jbc.M205324200

73. Truzzi F, Saltari A, Palazzo E, Lotti R, Petrachi T, Dallaglio K, et al. CD271 mediates stem cells to early progeny transition in human epidermis. J Invest Dermatol (2015) 135(3):786-95. doi:10.1038/jid.2014.454

74. Gutiérrez-Rivera A, Pavón-Rodríguez A, Jiménez-Acosta F, Poblet E, Braun $\mathrm{KM}$, Cormenzana $\mathrm{P}$, et al. Functional characterization of highly adherent CD34+ keratinocytes isolated from human skin. Exp Dermatol (2010) 19(7):685-8. doi:10.1111/j.1600-0625.2010.01075.x

75. Li A, Pouliot N, Redvers R, Kaur P. Extensive tissue-regenerative capacity of neonatal human keratinocyte stem cells and their progeny. J Clin Invest (2004) 113(3):390-400. doi:10.1172/JCI19140

76. Schlüter $\mathrm{H}$, Kaur $\mathrm{P}$. In vivo transplantation assay at limiting dilution to identify the intrinsic tissue reconstitutive capacity of keratinocyte stem cells and their progeny. Methods Mol Biol (2013) 989:165-82. doi:10.1007/978-1-62703-330-5_14

77. Jia HY, Shi Y, Luo LF, Jiang G, Zhou Q, Xu SZ, et al. Asymmetric stem-cell division ensures sustained keratinocyte hyperproliferation in psoriatic skin lesions. Int J Mol Med (2016) 37(2):359-68. doi:10.3892/ ijmm.2015.2445

78. Castelijns FA, Gerritsen MJ, van Erp PE, van de Kerkhof PC. Cell-kinetic evidence for increased recruitment of cycling epidermal cells in psoriasis: the ratio of histone and Ki-67 antigen expression is constant. Dermatology (2000) 201(2):105-10. doi:10.1159/000018471

79. Grabe N, Neuber K. Simulating psoriasis by altering transit amplifying cells. Bioinformatics (2007) 23(11):1309-12. doi:10.1093/bioinformatics/ btm042

80. Franssen ME, Zeeuwen PL, Vierwinden G, van de Kerkhof PC, Schalkwijk J, van Erp PE. Phenotypical and functional differences in germinative subpopulations derived from normal and psoriatic epidermis. J Invest Dermatol (2005) 124(2):373-83. doi:10.1111/j.0022-202X.2004.23612.x

81. Lippens S, Kockx M, Knaapen M, Mortier L, Polakowska R, Verheyen A, et al. Epidermal differentiation does not involve the pro-apoptotic executioner caspases, but is associated with caspase-14 induction and processing. Cell Death Differ (2000) 7(12):1218-24. doi:10.1038/sj.cdd.4400785

82. Truzzi F, Marconi A, Lotti R, Dallaglio K, French LE, Hempstead BL, et al. Neurotrophins and their receptors stimulate melanoma cell proliferation and migration. J Invest Dermatol (2008) 128(8):2031-40. doi:10.1038/jid. 2008.21 
83. Ordóñez NG. Value of melanocytic-associated immunohistochemical markers in the diagnosis of malignant melanoma: a review and update. Hum Pathol (2014) 45(2):191-205. doi:10.1016/j.humpath.2013.02.007

84. Miller DD, Emley A, Yang S, Richards JE, Lee JE, Deng A, et al. Mixed versus pure variants of desmoplastic melanoma: a genetic and immunohistochemical appraisal. Mod Pathol (2012) 25(4):505-15. doi:10.1038/ modpathol.2011.196

85. Sigal AC, Keenan M, Lazova R. p75 nerve growth factor receptor as a useful marker to distinguish spindle cell melanoma from other spindle cell neoplasms of sun-damaged skin. Am J Dermatopathol (2012) 34:145-50. doi:10.1097/DAD.0b013e318225b596

86. Alamodi AA, Eshaq AM, Hassan SY, Al Hmada Y, El Jamal SM, Fothan AM, et al. Cancer stem cell as therapeutic target for melanoma treatment. Histol Histopathol (2016) 31(12):1291-301. doi:10.14670/HH-11-791

87. Nishimura EK, Jordan SA, Oshima H, Yoshida H, Osawa M, Moriyama M, et al. Dominant role of the niche in melanocyte stem-cell fate determination. Nature (2002) 416(6883):854-60. doi:10.1038/416854a

88. Shakhova O. Neural crest stem cells in melanoma development. Curr Opin Oncol (2014) 26(2):215-21. doi:10.1097/CCO.0000000000000046

89. Boiko AD, Razorenova OV, van de Rijn M, Swetter SM, Johnson DL, Ly DP, et al. Human melanoma-initiating cells express neural crest nerve growth factor receptor CD271. Nature (2010) 466(7302):133-7. doi:10.1038/ nature09161

90. Quintana E, Shackleton M, Foster HR, Fullen DR, Sabel MS, Johnson TM, et al. Phenotypic heterogeneity among tumorigenic melanoma cells from patients that is reversible and not hierarchically organized. Cancer Cell (2010) 18(5):510-23. doi:10.1016/j.ccr.2010.10.012
91. Boyle SE, Fedele CG, Corbin V, Wybacz E, Szeto P, Lewin J, et al. CD271 expression on patient melanoma cells is unstable and unlinked to tumorigenicity. Cancer Res (2016) 76(13):3965-77. doi:10.1158/0008-5472. CAN-15-2377

92. Marconi A, Borroni RG, Truzzi F, Longo C, Pistoni F, Pellacani G, et al. Hypoxia-inducible factor- $1 \alpha$ and CD271 inversely correlate with melanoma invasiveness. Exp Dermatol (2015) 24(5):396-8. doi:10.1111/exd.12679

93. Saltari A, Truzzi F, Quadri M, Lotti R, Palazzo E, Grisendi G, et al. CD271 down-regulation promotes melanoma progression and invasion in three-dimensional models and in zebrafish. J Invest Dermatol (2016) 136(10):2049-58. doi:10.1016/j.jid.2016.05.116

94. Selimovic D, Sprenger A, Hannig M, Haïkel Y, Hassan M. Apoptosis related protein-1 triggers melanoma cell death via interaction with the juxtamembrane region of p75 neurotrophin receptor. J Cell Mol Med (2012) 16(2):349-61. doi:10.1111/j.1582-4934.2011.01304.x

Conflict of Interest Statement: The author declares that the research was conducted in the absence of any commercial or financial relationships that could be construed as a potential conflict of interest.

Copyright (c) 2017 Pincelli. This is an open-access article distributed under the terms of the Creative Commons Attribution License (CC BY). The use, distribution or reproduction in other forums is permitted, provided the original author(s) or licensor are credited and that the original publication in this journal is cited, in accordance with accepted academic practice. No use, distribution or reproduction is permitted which does not comply with these terms. 